\title{
Characterization of Fontainebleau Sandstone: Quartz Overgrowth and its Impact on Pore-Throat Framework
}

Faisal Al Saadi*, Karl-Heinz Wolf and Cor van Kruijsdijk

Shell International Exploration and Production BV, Delft University of Technology, Netherlands

\begin{abstract}
Fontainebleau sandstone outcrop is a prime example of a simple natural porous medium because of its pure mineral composition (0.995 Quartz) and an almost constant grain size in large sample blocks. It is widely used to investigate the correlation between the simple petrophysical properties independently of other parameters.

This paper shows an experimental evaluation of Fontainebleau sandstone properties and their characteristics to advance understanding on the quartz overgrowth and the petrophysical and electrical transport properties. In order to acquire the pore and grain frameworks, we measure and quantify spatial attributes of the grain and pore's matrix by Computed Tomography (CT) image analysis, associated to stereological measurements and statistical 2D/3D reconstructions. In addition, the regular petrophysical laboratory methods are applied and connected to the spatial results. Furthermore, our graphical methods are compared to pre-existing literature. The main contribution of this work is the impact of quartz overgrowth on the pore-throat framework.

Our laboratory experimental measurements provide comprehensive information in petrophysical and petrological data of Fontainebleau sandstone. We conclude that Fontainebleau sandstone outcrop displays consistent and homogenous properties. The clay in the studied samples of Fontainebleau sandstone are almost not exists and does not play any role in the pore framework. This ensures repeatability and reproducibility of our flow experiments in porous media. It provides comparable core flow experimental in our study of the oil mobilization process in the porous media. We demonstrated that the quartz overgrowth (i.e. cementation) is playing a central role in the porethroat geometry and impacts both permeability and porosity by reducing the pore-throats (i.e. coordination number).
\end{abstract}

Keywords: Pore framework; Fontainebleau sandstone; Quartzovergrowth; Cementation; Dielectric; Clay; Porosity; Permeability

\section{Introduction}

Fontainebleau sandstone outcrops in South Paris in France (Figure 1). Its base consists of a marine beach and its top contains aeolian dune sands $[1,2]$. It is considered to be one of the simplest natural porous media as it displays constant and regular pore and grain framework (i.e. spatial) properties [3]. This ensures reproducibility of flow experiments in porous media and minimizes changes in its properties.

The geology, petrology, petrophysics, and associated reservoir geology of Fontainebleau sandstone are well known [1-3]. There is a plethora of petrophysical data in scientific literature. This fact and the homogeneous parameters (i.e. constant pore/grain sizes and absence of the clay) we need for our flow experiments, motivate us to further examine the distributions regarding the spatial characteristics, matrix mineralogy and petrophysical parameters such as permeability, porosity, capillarity, pore framework, pore-network, coordination distribution, etc. Hence our findings are compared with results from literature [4-7]. In addition, we focus on overcoming the shortcomings in the literature (i.e., the impact of quartz overgrowth on pore-throat framework with a use of micro-CT, determination of the grain size distribution with a use of micro-CT scanner, Scanning Electron Microscopy (SEM) and Mercury Injection Capillary Pressure (MICP) analysis).

In this study, we measure and quantify spatial attributes of the grain and pore's matrix by Computed Tomography (CT) image analysis, associated to stereological measurements and statistical $2 \mathrm{D} / 3 \mathrm{D}$ reconstructions. This enables us to acquire the pore and grain frameworks. In addition, the regular petrophysical laboratory methods are applied and connected to the spatial results. Furthermore, our graphical methods are compared to pre-existing literature. We use

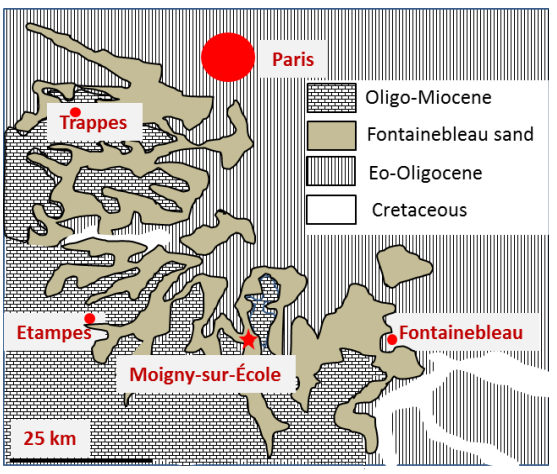

Figure 1: The layout of Fontainebleau sandstone. The Grès de Fontainebleau \& Cie quarry in Moigny-sur-École for rock sampling (Quarry coordinates: 48.434237,2.433944). Modified after [3]

X-Ray devices (like Micro-CT, XRF/XRD, SEM) to determine mineral phases, and grain/pore surface attributes. They support the geochemical processes associated to the burial stage. Moreover, new polished thin

"Corresponding author: Faisal Al Saadi, Shell International Exploration and Production BV, Wassenaar, Den Hague, Netherlands, Tel: +31152781328; E-mail: f.alsaadi@shell.com

Received March 28, 2017; Accepted June 10, 2017; Published June 17, 2017

Citation: Al Saadi F, Wolf K, Kruijsdijk CV (2017) Characterization of Fontainebleau Sandstone: Quartz Overgrowth and its Impact on Pore-Throat Framework. J Pet Environ Biotechnol 7: 328. doi: 10.4172/2157-7463.1000328

Copyright: @ 2017 Al Saadi F, et al. This is an open-access article distributed under the terms of the Creative Commons Attribution License, which permits unrestricted use, distribution, and reproduction in any medium, provided the original author and source are credited. 
sections are used to validate the XRD/XRF-results by petrography. We think of shifts in grain/pore size distribution, type of quartz overgrowth, and leaching effects. Additionally, porosity, permeability, conductivity, zeta potential, and capillary pressure measurements have been included to support the understanding of the geochemical and petrophysical properties.

The petrophysical results are needed for volumes ranging in scale from micrometer to meter. It provides essential information on the microstructural properties of the pore framework with associated heterogeneities and its flow behavior for various sample sizes. Knowing the results for this scale-window of Fontainebleau sandstone allows us to assign bulk electrical properties, permeability and spatial characteristics to modelling parameters.

This paper starts with detailed literature review on the existing data of Fontainebleau sandstone which covers the regional geology, petrology, stratigraphy, petro-physics, pore framework, capillarity and dielectric properties. Then, we explain the experimental equipment, methods and procedures that we carry out for data gathering and interpretation. After that we present our data, results and discussion. We conclude the article by summarizing the results and drawing the conclusions.

\section{Literature review}

\section{Regional Geology}

Fontainebleau sandstone occurs south of Paris and covers the central part of the Paris Basin (Figure 1). It is of Rupelian age (24-34 $\mathrm{Ma}$ ) and usually $50-60 \mathrm{~m}$ in thickness. It is a fine-grained, well-sorted sandstone. The sandstone overlies the Mesozoic (Cretaceous deposits) in the center of the Basin.

\section{Stratigraphy}

The upper part of the Fontainebleau sandstone extends laterally for tens of kilometers in the Paris Basin and its thickness is approximately 10 meters. It is white in color due to water leaching over the past 30,000 years and it is considered to have originated from aeolian dunes. The base of the Fontainebleau sandstone (Figure 2) is marine's deposits and Thirty contains mostly quartz and some clay [2]. According to Dollfus [9] and [2], dark glauconite, organic- and pyrite-rich sands were formed when the unit was below the water table. The block that we are characterizing originates from the white upper part, from an outcrop in the Grès de Fontainebleau \& Cie quarry in Moigny-sur-École, Essonne, $90 \mathrm{~km}$ south of Paris (Figure 1). These aeolian sandstone blocks have been leached.

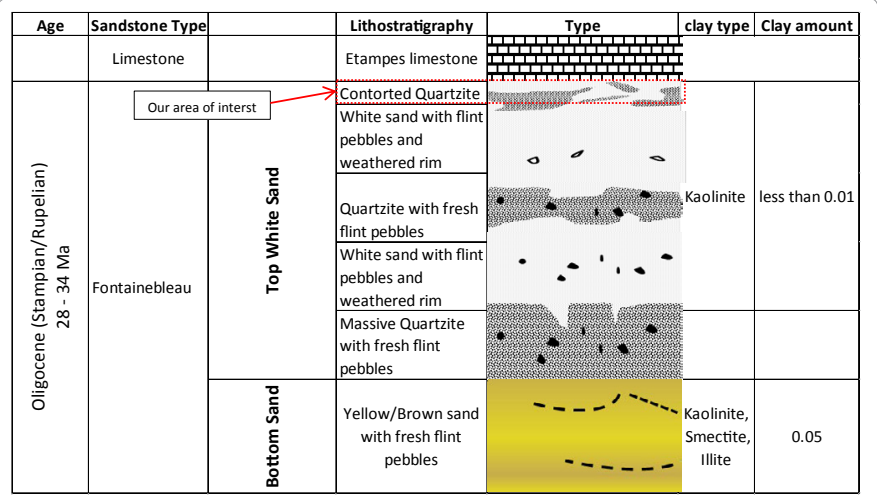

Figure 2: Fontainebleau cross section (Modified after: [3])

\section{Petrography}

Bottom sand section: The sand at the bottom of the formation's base is a yellow and brown coloured section, containing approximately $5 \%$ clay which is a combination of kaolinite, illite, and smectite. As we move up the formation base the amount of clay decreases, and illite and smectite disappear leaving only kaolinite $[2,8,10]$. Due to its heterogeneity, the base is exempt from our experiments and is not considered to be relevant for this article.

Top white sand section: The sand at the top of the formation, the white sand section, is very clean and at first sight does not contain any clay minerals. It consists of more than $99.5 \% \mathrm{SiO}_{2}$ in the form of quartz minerals $[2,8,10]$.

Quartzite lenses in the white sand section: Silification in Fontainebleau sandstone produced very strongly cemented sandstones or sedimentary quartzite lenses at a former water table [2]. They consist of partly dissolved quartz grains with secondary quartz overgrowth. In addition, microcrystalline quartz (chalcedony) is the subordinate silica phase. The overgrowth may reach as much as 0.35 in volume, and has average values from 0.15 to $0.20[2,11,12]$.

\section{Petrophysics}

Zinszner presented two groups with different permeability-porosity relations that are recognized in Fontainebleau sandstone [13]. In cases of high porosities $(\phi>0.08-0.09)$, for a given porosity the average grain sizes are constant and the specific surface area and tortuosity are independent of porosity. As a result, according to Zinszner [13], the Carman-Kozeny model leads to permeability proportional to $\phi^{3}$. In cases of low porosity $(\phi<0.08-0.09)$, some of the pores remain relatively large, while the pore throats are cemented gradually by quartz overgrowth and may disappear [4,13]. Fredrich [5] states that porosity reduction in Fontainebleau sandstone was accomplished over geologic times by dissolution and precipitation of silica from mobile pore fluids. The silica may have originated from outside the formation. Cooper suggest that the porosity reduction is related to mechanical compaction, which acted homogeneously. It is likely that cementation occurred prior to completion of mechanical compaction.

\section{Pore Framework and Connection}

Fontainebleau sandstone is well sorted with grain size distributions in the range of $150-300 \mu \mathrm{m}$, and with a wide range of porosities between $0.02-0.3[3,4,14]$. In the literature, pore bodies diameter appears to range from 16 to $30 \mu \mathrm{m}$.

\section{Electrical Conductivity}

The brine is the main contributor of the electrical conduction in a saturated porous media, i.e. high amounts of charged cations and anions $[15,16]$. However, additional contributions are made by the pore framework such as effective porosity and tortuosity and mineral heterogeneity by the most probable presence of accessory oxides [17]. Contributions are also made by the degree of brine saturation, i.e. the percentage of pore occupation by conductive fluids [18].

Archie [19] defined the correlation between the conductivity of the pore fluid and the bulk conductivity of fully-saturated mono-mineral clean sandstones by introducing formation factor $\mathrm{F}$, which is related to porosity through eq.1:

$$
F=C_{w} / C_{o}=\alpha / \varphi^{m}
$$

Where 
$C_{w}=$ Conductivity of fully water saturated rock, $\mu \mathrm{S} / \mathrm{cm}$

$C_{o}=$ Saturating water conductivity, $\mu \mathrm{S} / \mathrm{cm}$

The $m$ and a coefficients, known as the cementation exponent and $a$ texture factor, are usually determined empirically. Schon [15] reports that both parameters are controlled by pore channel geometry, including pore shape and connectivity. Worthington [20] provides a range of $\alpha$ and $m$ values based on Timur [21]: degree of cementation, shape, sorting and packing of grains, type of porosity, tortuosity, pressure, wettability of rock surface, pore geometry, and clay content.

Note that the conductivity of a brine saturated rock is proportional to brine conductivity for clean sand (silica with no clays) like the Fontainebleau sandstone. Gomez [22] reports a cementation exponent in the range of $1.8-2.1$. Similarly, Revil [23] presented a cementation exponent between $1.4-2$, while Borner reports 2 samples of Fontainebleau with a cementation factor of $1.6-1.7$ [24].

\section{Samples and Methods}

\section{Samples}

For this study, a site visit to the Gres de Fontainebleau \& Cie quarry near Fontainebleau provided us with five large blocks of different sizes $\left(0.008 \mathrm{~m}^{3}\right.$ to $\left.0.04 \mathrm{~m}^{3}\right)$ weighing about 1 ton in total. One of the blocks $\left(0.018 \mathrm{~m}^{3}\right)$ has been characterized regarding its porosity, permeability, by analyzing 70 samples. Those samples are cylindrical with a diameter of $3 \mathrm{~cm}$ and a length of $3.4 \mathrm{~cm}$. They have been used to quantify the lateral and vertical variation within the block.

For spatial characteristics, two pencil type samples, $120 \mathrm{~mm}$ in length and with a diameter of $6.7 \mathrm{~mm}$ (or ca. 30 grains width) have been used to do the micro-CT.

Conductivity measurements have been done on 9 different samples with a diameter of $1.5 \mathrm{~cm}$ and a length of $3 \mathrm{~cm}$. The porosity of the samples is in range of 0.07 to 0.1 , with $\mathrm{NaCl}$ brine salinities varying from $30 \mathrm{ppm}$ to $60000 \mathrm{ppm}$ as shown in Table 1 .

\begin{tabular}{|c|c|c|c|c|c|c|c|c|c|}
\hline Sample & $5 \mathrm{~A} 1$ & $4 \mathrm{~B} 1$ & $4 \mathrm{~A} 2$ & $4 \mathrm{~A} 3$ & $4 \mathrm{~B} 2$ & $5 \mathrm{~B} 5$ & $4 \mathrm{~A} 1$ & $5 \mathrm{~A} 5$ & $4 \mathrm{~B} 3$ \\
\hline Porosity & 0.094 & 0.084 & 0.083 & 0.079 & 0.078 & 0.078 & 0.074 & 0.072 & 0.069 \\
\hline Permeability & 24 & 20 & 16 & 21 & 12 & 28 & 12 & 16 & 12 \\
\hline
\end{tabular}

Table 1: Properties of the samples used for conductivity measurements.

For the centrifuge and MICP measurements, 6 samples have been prepared with the properties mentioned in Table 2 . To get confidence that the MICP samples are representative, we cut $1 \mathrm{~cm}$ piece on top and at the bottom of the 6 samples. From these slices the MICP samples are taken. Note that the samples for the centrifuge measurements are with a diameter of $3.8 \mathrm{~cm}$ and a length of $5 \mathrm{~cm}$.

\begin{tabular}{|c|c|c|c|c|c|c|}
\hline Sample & WM1 & VL1 & UB1 & RI1 & SH1 & TA1 \\
\hline Porosity & 0.08 & 0.092 & 0.082 & 0.071 & 0.062 & 0.099 \\
\hline Permeability & 92 & 133 & 87 & 32 & 18 & 240 \\
\hline
\end{tabular}

Table 2: Properties of the samples used for centrifuge and MICP measurements.

The streaming potential measurements have been done on a core of $17 \mathrm{~cm}$ length and diameter of $3.8 \mathrm{~cm}$. Its porosity is on 0.09 and permeability of $120 \mathrm{mD}$.

\section{Methods of Analysis}

Several techniques and methods are used to characterize the petrography and petrophysical parameters of the chosen block. Those methods are categorized under image analysis procedures to process 2D/3D images \& laboratory procedures.

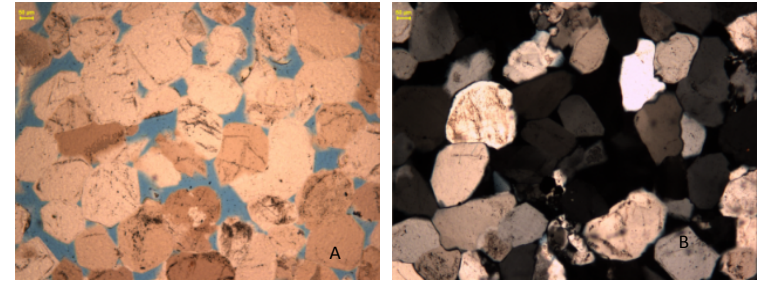

Figure 3: A: Fontainebleau thin section image. B: Image with polarized light.
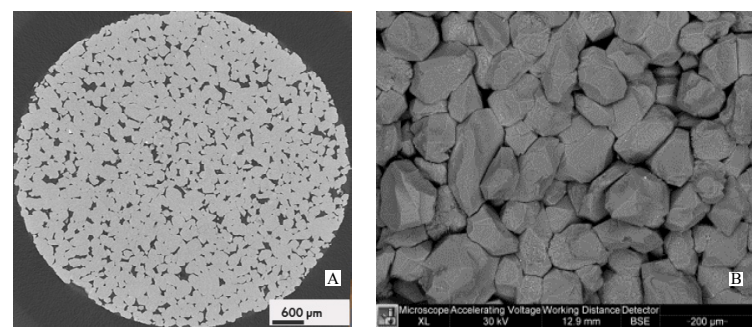

Figure 4: Fontainebleau images, A: Micro-CT, B: SEM.

\section{Petrography}

Thin sections: Polished thin sections with blue dye impregnation and covered with glass (Figure 3) were prepared for petrographical characterization and quantification. Two-dimensional mineral composition, pore and grain size distribution, and mineral growth phases were studied. For the image acquisition and quantification we used a Leica Camera, Polarization/fluorescence microscope and Qwin image analysis software.

\section{Micro-CTS and Scanning Electron Microscopy (SEM)}

A Phoenix Nanotom ${ }^{\text {tx }}$ Micro-CT scanner (mCT) was used to create 2D stacks of Fontainebleau sandstone (Figure 4a). Its maximum voxel resolution of $<5 \mu \mathrm{m}$. Also, several photos at different magnification/ scale were taken using scanning electron microscopy (Philips FEG XL40, equipped with Apollo EDX detector) (Figure 4b).

XRD: X-Ray diffraction is used to identify the crystallographic nature of minerals, irrespective of their chemical composition. The set-up consisted of a Bruker D8 advance diffractometer and a Lynxeye position sensitive detector, with $\mathrm{Cu}$ Ka radiation. Moreover, it indicates the presence of amorphous phases and indicates the approximate abundance of different mineral phases.

XRF: The X-ray fluorescence measurements were performed with a Panalytical Axios Max WD-XRF spectrometer and data evaluation was done with SuperQ5.0i/Omnian software. Powder was pressed into a tablet with binder and measured in vacuum. The X-ray fluorescence analysis provides the chemical composition of the oxidized elements in weight $\%$.

XRD/XRF combination: By combining XRD mineral content and XRF element distribution, synthetic mineral composition can be reconstructed in weight $\%$, volume $\%$ and mole $\%$. The method is explained by Wolf [25].

\section{Image analysis}

Analysis of the 2D and 3D discrete images from the thin sections, SEMs and micro CT were performed to determine the grain and pore size distributions, specific surface area, pore-throat size distribution and channel lengths. Furthermore, 2D thin section image analysis 
was performed using polarization microscopy. This method is used to identify mineral grain perimeters by their polarization color and extinction angle. In addition, simple pore/grain distribution is possible with point counting of about $100-120$ random points in each thin section. The proportion of each mineral in the rock and, consequently, the quantitative mineralogical composition are obtained by mineralogical determination at each randomly selected point. The stacked 3D volumes were reconstructed with AVIZO ${ }^{\text {twx }}$ software.

\section{Petrophysics}

Porosity and Permeability measurements: The dry porosity measurements were done with a pycnometer. The pycnometer is a device that measures the volume of solid particles of a sample using Boyle's law. The permeability measurements were done using the Ruska permeameter which is a device that forces the flow at a specific pressure through the sample. The permeability is calculated using Darcy's equation.

Di-electrical measurements: Conductivities were measured at $23{ }^{\circ} \mathrm{C}$ on fully saturated samples with different, known brine conductivities. All samples were fully evacuated before saturation. The sample was then placed into an insulator and the conductivity of the saturated core samples was measured, in order to determine the formation and cementation factors. Figure 5 presents the description of the conductivity's setup.

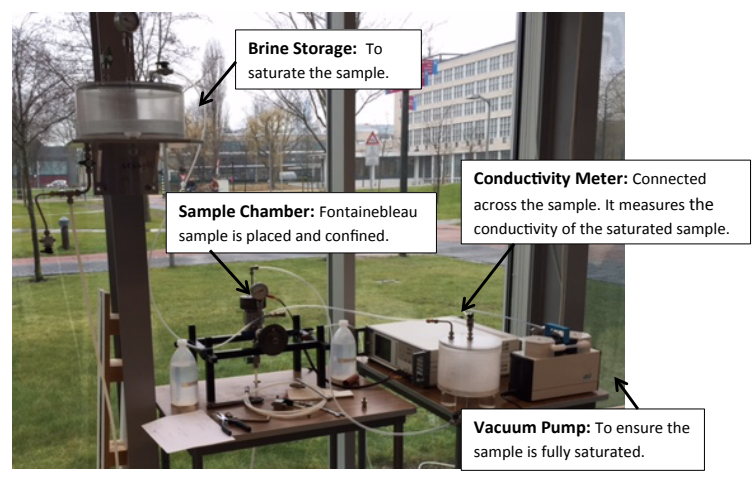

Figure 5: Set-up for measuring conductivity.

Zeta potential: Zeta potential describes the surface charge of the particle, and the nature and composition of the surrounding suspension which, in turn, depends on the surface chemistry and the ionic concentration of the bulk solution [26].

Zeta potential gives a good indication of the magnitude of the electrostatic repulsive interaction between particles [27]. Lorey [28] presents it as a physiochemical parameter, which describes the ion adsorption and double layer interactions between charged particles and provides important details on the electrochemical properties of the electrical double layer (EDL) [28].

The electrical double layer of a charged surface is formed by the redistribution of ions in the surrounding medium (electrolyte). The origin of surface charge may be caused by:

- Ionization of the surface

- Differential dissolution of ions from insoluble crystals

- Isomorphic substitution of ions

- Changes in crystal surface

- Specific adsorption of species
Sandstones (including Fontainebleau sandstone) are negatively charged and their zeta potential is a negative value.

The zeta potential measurements are carried out in a Malvern Zetasizer-nano ZS90. Zeta potential is measured using a combination of electrophoresis and laser doppler velocimetry. To increase sensitivity, the instrument uses both the Mixed Mode Measurement (M3) and the Phase Analysis Light Scattering (PALS) techniques.

The essence of a classical micro-electrophoresis system is a cell with electrodes at either end, filled with brine and crushed sandstone sample material, to which a potential is applied. Particles move towards the electrode of opposite charge, and their velocity and size are measured and expressed in unit field strength as being their mobility by using laser-Doppler techniques.

Capillary pressure: Capillary pressure is considered to be the elementary parameter to describe the behavior of two or more immiscible fluid phases in the porous media. The capillary pressure presents the static force between the non-wetting phase and wetting phase in the porous media and it is an increasing function of the nonwetting phase saturation $[29,30]$.

Pickell [31] highlighted that for water-wet rocks (i.e. like Fontainebleau), capillary forces predominate in the distribution of fluids and that viscous forces in the range normally of interest in the reservoir have a minimum influence on residual oil saturation [31].

Capillary pressure curves have been measured by centrifuge (Figure 6a), and mercury intrusion porosimetry (MICP) (Figure 6b). Porous plate technique is the most accurate, however, it was not used since it was time consuming as it could take more than 20 weeks to acquire an oil-water drainage curve [32,33].

Multi-speed centrifuge experiments: Hassler and Brunner proposed a fast method to set up the saturations in a high-speed centrifuging. The core sample is placed into a centrifuge tube and rotated at a number of different speeds selected to cover pressure differences between phases required for the particular cores. At each step, the rate of rotation is maintained constant until phase stabilization.

Mercury Injection Capillary Pressure (MICP) analysis: MICP directly measures pore volume distribution by forcing $\mathrm{Hg}$ (mercury) into pore space. The injection determines the sample's interconnected pore system and the size distribution of pore apertures (capillaries) that strongly influence the non-wetting phase (e.g. hydrocarbon) saturations and fluid flow (e.g. permeability). MICP measures porethroat size distribution, total pore volume, total pore surface area, sample density and imbibition/drainage capillary pressure data.
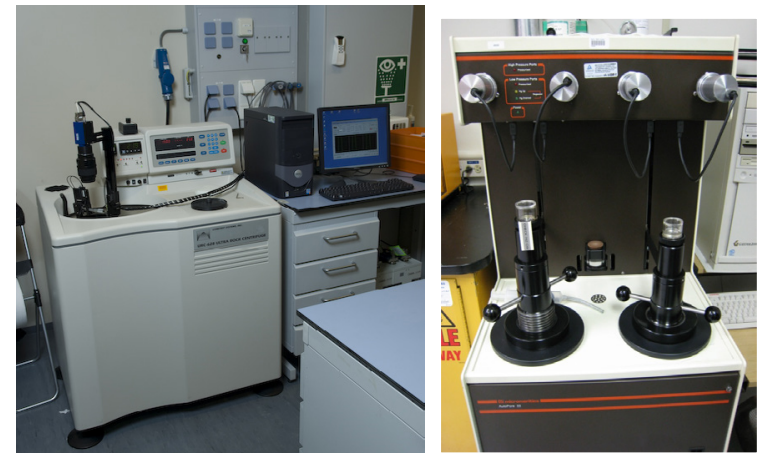

Figure 6: A: Centrifuge experiment, B: Micromeritics autopore IV. 


\section{Results and Discussion}

Our experimental results, presented here below, are when possible explained and discussed in relation to the data available from literature. Most conclusions will also be stated as a comparison between our work and other academic literature.

\section{Petrography, Mineralogy and Texture}

XRD-XRF results: The detected XRD mineral is only quartz (Figure 7). XRF shows trace amounts of other oxides (Table 3). After processing the XRD and XRF data by using MINCOMP software (Wolf, 2006), the synthetically reconstructed clays are illites (0.0015) and kaolinite (0.0039).

Thin section results: Scanning the images with polarized light showed that visually only quartz is present and no clays are found in the pores (Figure 8). Moreover, as inclusions in the overgrowth quartz, some dirt, oxides and clays may be available. They are, however, not connected to any of the pores.

SEM results: Using spot analysis, accessory clay was examined in several areas $(1-6)$ as shown in Figure 9. All results indicate that the minerals are mostly quartz with minor traces of clay at fractured interfaces and not on the pore-walls (See 1 and 2 of the polished sample (Figure 9a) where the small amount of aluminum is indicated).

Quartz Overgrowth: Quartz-overgrowth clearly dominates the

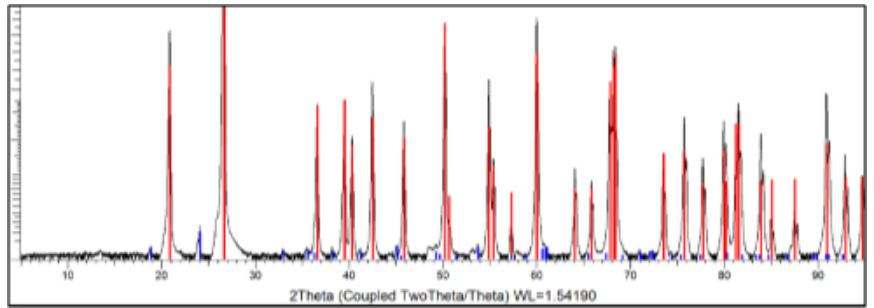

Figure 7: The measured XRD pattern in black, after background subtraction. The red lines are peak positions and intensities of known mineral phases. Only quartz was found; the extra peaks, indicated with the blue stick pattern, are due to the $\mathrm{Kb}$ contribution in the incident $\mathrm{X}$-ray beam.

\begin{tabular}{|c|c|c|c|}
\hline Compound & \multicolumn{2}{|c|}{ Concentration \% } & Absolute Error \% \\
\hline Silica $\mathrm{SiO}_{2}$ & \multicolumn{2}{|l|}{99.451} & \\
\hline Aluminium Oxide $\left(\mathrm{Al}_{2} \mathrm{O}_{3}\right)$ & \multicolumn{2}{|l|}{0.246} & 0.01 \\
\hline Iron III Oxide $\left(\mathrm{Fe}_{2} \mathrm{O}_{3}\right)$ & \multicolumn{2}{|l|}{0.056} & 0.007 \\
\hline Calcium Oxide $(\mathrm{CaO})$ & \multicolumn{2}{|l|}{0.052} & 0.007 \\
\hline Sodium Oxide $\left(\mathrm{Na}_{2} \mathrm{O}\right)$ & \multicolumn{2}{|l|}{0.035} & 0.006 \\
\hline Sulphur Trioxide $\left(\mathrm{SO}_{3}\right)$ & \multicolumn{2}{|l|}{0.033} & 0.005 \\
\hline Titanium Dioxide $\left(\mathrm{TiO}_{2}\right)$ & \multicolumn{2}{|l|}{0.031} & 0.005 \\
\hline Chloride $(\mathrm{Cl})$ & 0.023 & \multicolumn{2}{|r|}{0.005} \\
\hline Magnesium Oxide (MgO) & \multicolumn{2}{|l|}{0.023} & 0.005 \\
\hline Phosphorous Pentoxide $\left(\mathrm{P}_{2} \mathrm{O}_{6}\right)$ & 0.019 & & 0.004 \\
\hline Potassium Oxide $\left(\mathrm{k}_{2} \mathrm{O}\right)$ & 0.014 & \multicolumn{2}{|r|}{0.004} \\
\hline Reconstructed Minerals & Mole & Weight & Volume \\
\hline Quartz & 0.9972 & 0.9903 & 0.9906 \\
\hline kaolinite & 0.0009 & 0.0038 & 0.0039 \\
\hline Ilite & 0.0002 & 0.0015 & 0.0015 \\
\hline Pure Albite & 0.0003 & 0.0013 & 0.0013 \\
\hline Chloride & 0.0001 & 0.0008 & 0.0008 \\
\hline Calcite & 0.0003 & 0.0005 & 0.0005 \\
\hline Siderite & 0.0002 & 0.0004 & 0.0003 \\
\hline
\end{tabular}

Table 3: XRF Data and Reconstructed Minerals

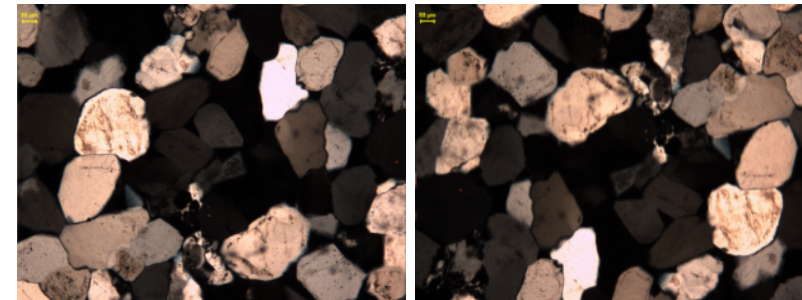

Figure 8: Images with polarized light: crossed Nicolls; the view field length is $1 \mathrm{~mm}$.
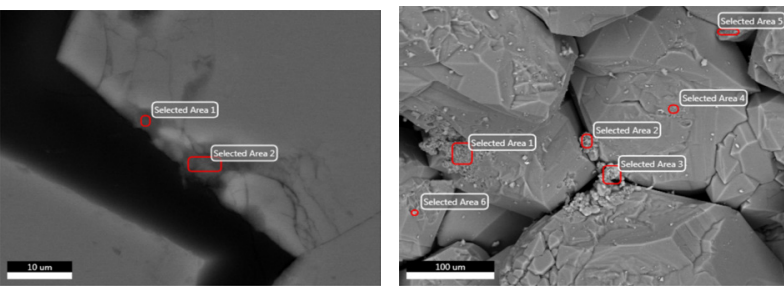

Figure 9: Selected Areas via SEM to examine the presence of clay.
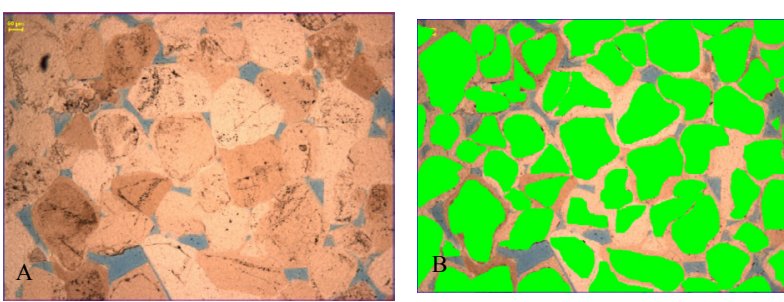

Figure 10: A. Quartz overgrowth around original "dirty" grains: the fines in the overgrowth part represent the rims of the grain shape before quartz overgrowth started. B. Definition of the original grain core (green) in the right image; the beige color shows the overgrowth, blue represents the pore space.
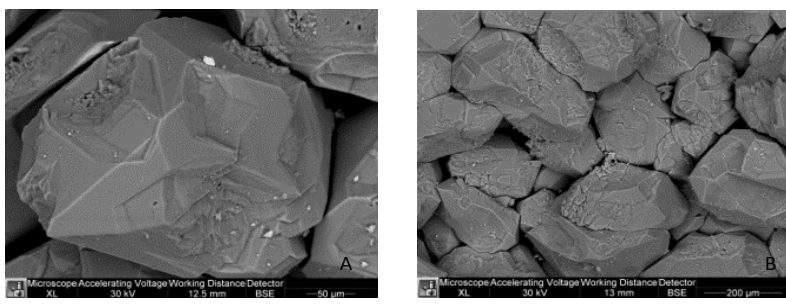

Figure 11: SEM images, angular surface and sharp edges due to the quartz overgrowths.

cementation around the original detrital quartz grains (Figure 10a). Based on image quantification, the measured overgrowth is estimated to be around 0.15 for high porous sandstones, increasing to 0.20 for lower porosities. The overgrowth in these lenses may reach as much as 0.35 of the bulk volume. The strength of the rock correlates positively with decrease in porosity and increase in quartz overgrowth. Figure 11 shows angular surface and sharp edges due to the quartz overgrowths.

It can be concluded that $\mathrm{XRF} / \mathrm{XRD}$, polarization microscopy and SEM confirm that Fontainebleau sandstone consists of almost pure quartz (over $99.5 \% \mathrm{SiO}_{2}$ ) with very clear quartz overgrowth starting from a smaller grain that is represented by the inclusions. The amount of clay is less than 0.005 and has not been observed in thin sections or SEM at a pore face. This result is in line with the literature $[2,11,12]$. Quartz overgrowth is evident and causes the reduction in porosity by reducing the pore throat size. 
Citation: Al Saadi F, Wolf K, Kruijsdijk CV (2017) Characterization of Fontainebleau Sandstone: Quartz Overgrowth and its Impact on Pore-Throat Framework. J Pet Environ Biotechnol 7: 328. doi: 10.4172/2157-7463.1000328

Page 6 of 12

Pore and Grain Framework: For the two clusters of porosities in our sandstone sample (0.06 and 0.10), micro-images from thin sections, micro-CT and SEM, (Figure 12) were prepared and analyzed on their spatial characteristics.

Comparison of the two different thin sections (Figure 12, Table 4), shows that the pore area hardly changes but the pores' throats reduce in area. It results in a slight reduction in porosity and a more significant reduction in permeability. The CT-scan pore area distribution (Figures $12 \mathrm{c}, 12 \mathrm{~d}$ ) and the SEM surface images (Figures 12e, 12f) confirm this statement.

The analysis of the grain size distributions via thin section and micro-CT shows constant range of 100-300 $\mu \mathrm{m}$ (Figure 13b). Figure 13a presents the constant pore body size distributions despite the change in the porosities.

In summary, results and comparisons between micro CT, SEM and thin sections indicate almost constant pore size and grain size distributions. The grain diameters are in the $100-300 \mu \mathrm{m}$ range; the pore sizes are in the 20-100 $\mu \mathrm{m}$ range; the throat diametres vary between 10 $30 \mu \mathrm{m}$. These results are comparable with the literature (Table 5).

Pore framework plays a major role in controlling porosity. In the literature, pore space diameter appears to range from 16 to 30 $\mu \mathrm{m}$. When reduction in porosity occurs, it is caused by shrinkage of the pore throat diameter due to quartz overgrowth. For porosities between 0.1-0.2, the specific surface areas remain constant despite the
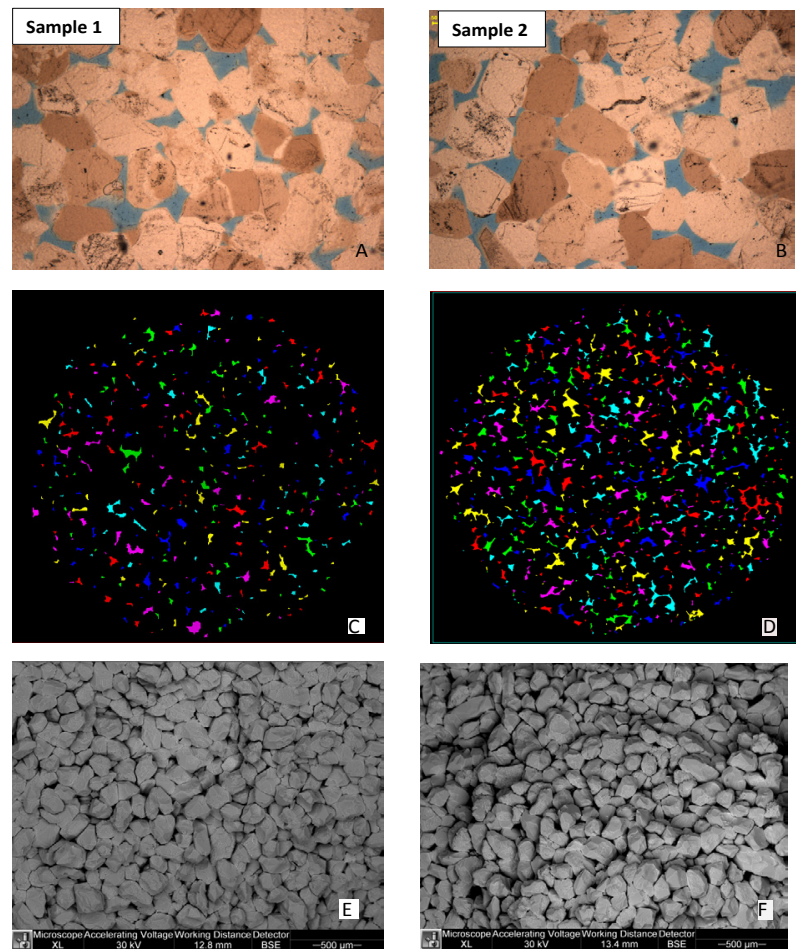

Figure 12: Thin sections (matrix grains and overgrowth and pores), MicroCT images (pore space detection) and SEM (grain framework surface characterization)

\begin{tabular}{|l|l|l|l|l|l|}
\hline & $\begin{array}{l}\text { Measured } \\
\text { porosity }\end{array}$ & $\begin{array}{l}\text { Image } \\
\text { porosity }\end{array}$ & $\begin{array}{l}\text { Grain size } \\
\text { distribution, } \\
\mu \mathrm{m}\end{array}$ & $\begin{array}{l}\text { Pore size } \\
\text { distribution, } \mu \mathrm{m}\end{array}$ & $\begin{array}{l}\text { Permeability } \\
\mathrm{mD}\end{array}$ \\
\hline Sample 1 & 0.06 & 0.063 & $100-300$ & $20-100$ & 18 \\
\hline Sample 2 & 0.101 & 0.104 & $100-300$ & $20-100$ & 250 \\
\hline
\end{tabular}

Table 4: Comparisons between two samples of Fontainebleau.
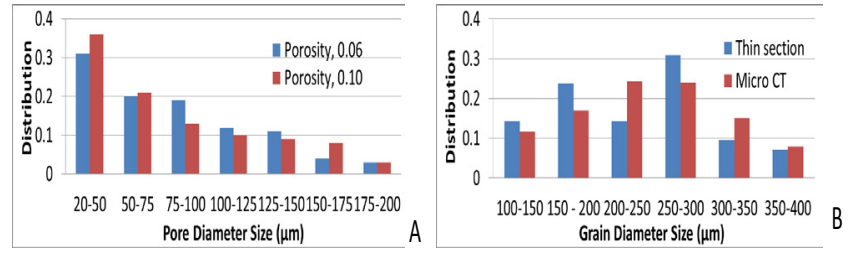

Figure 13: Pore and grain size distribution.

decrease in the solid-pore interface area [5]. This reduction in porosity creates angular mineral phase type pore shapes [5,7]. Permeability is dominated by tortuosity and coordination number of the pore bodies and is directly related to the previously mentioned quartz overgrowth in the pore framework.

\section{Petrophysics}

Permeability-Porosity relation: Within the sample block with dimentions of $30 \mathrm{~cm} \mathrm{X} 20 \mathrm{~cm} \mathrm{X} 20 \mathrm{~cm}, 70$ plugs were measured on their porosity and permeability, showing the variation sub-parallel to the stratification (Figure 14). In general, the permeability was between $10 \mathrm{mD}$ to $400 \mathrm{mD}$ and the porosity ranged from 0.05 to 0.15 .

The measured permeability and porosity of the samples (Figure 15) are consistent with Bourbie's data set [13]. Combining the experimental results of Bourbie [14], Doyen [4], Fredrich [5], Gomez [22], Reveil [23], and this study, an improved phi/k-relation was developed; $k=$ $10^{6,5+4,6 \times \log (\varphi)} ; \mathrm{R}^{2}=0.95 ;$. Note that the grain size distribution, degree of leaching and cementation were not considered for this relation.

Prediction of Fontainebleau Permeability with cementation following the Panda and Lake Model: Panda and Lake proposed a modified Carmen-Kozeny (CK) model [34, 35,36], which analytically relates the contribution of the particle size distribution statistics (i.e. mean, standard deviation and skewness) and the contribution of the types and amounts of various cementing clays present, to the permeability. We applied the model to calculate a theoretical permeability and compare it with the measured permeability.

$$
\begin{aligned}
& k=\left[\bar{D}_{P}^{2} \theta^{3}\left(\gamma C_{D_{P}}^{3}+3 C_{D_{P}}^{2}+1\right)^{2}\right] \\
& \left.\div\left\{2 \tau_{\mathrm{e}}(1-\theta)^{2}\left[6\left(1+C_{D_{P}}^{2}\right) \frac{1-\theta_{0}}{1-\theta}+\left(a_{v b} P_{b}+a_{v l} P_{l}+a_{v f} P_{f}\right) \bar{D}_{P}\left(\gamma C_{D_{P}}^{3}+3 C_{D_{P}}^{2}+1\right)\right]^{2}\right\}\right)
\end{aligned}
$$
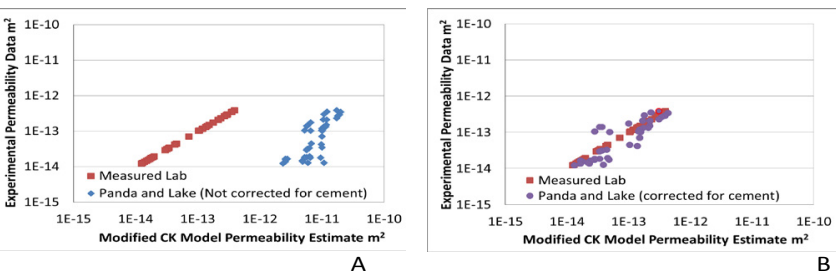

Figure 16: A. Variance between the permeability model estimation (not corrected for cement) versus the experimental data. B. Comparison but using the modified CK Model as proposed by Panda and Lake, which includes the effects of cements.

Following the steps of Panda and Lake, we first estimated the permeability using the original equation neglecting the effect of cements (Figure 16A). Thereafter the cement component was included (Figure 16B). It can be seen that the Panda and Lake Model estimate gives a good match with the experimental data. For our porous medium, it confirms that permeability is more influenced by the volume of cements than the parameters of particle size distribution. When implementing the modified equation, the contribution of the cementation-relation gives a good match. 
Citation: Al Saadi F, Wolf K, Kruijsdijk CV (2017) Characterization of Fontainebleau Sandstone: Quartz Overgrowth and its Impact on Pore-Throat Framework. J Pet Environ Biotechnol 7: 328. doi: 10.4172/2157-7463.1000328

Page 7 of 12

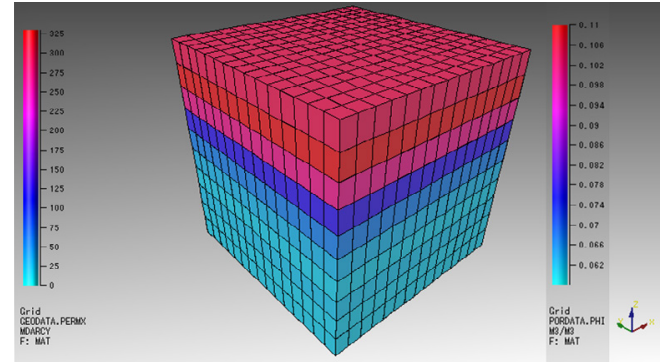

Figure 14: Permeability and Porosity variation within the block.

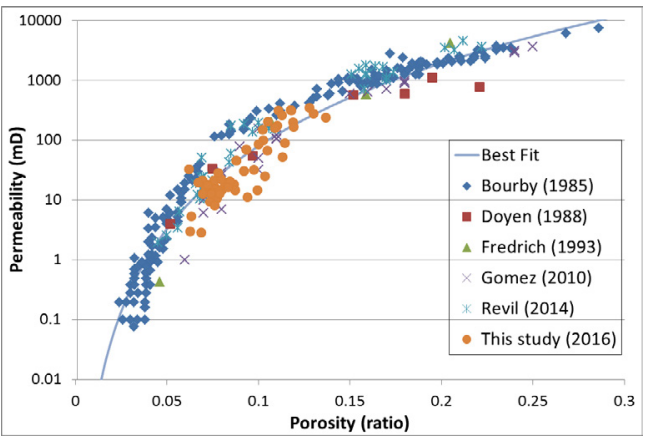

Figure 15: Porosity vs Permeability of Fontainebleau sandstone.

MICP and centrifuge: Fontainebleau pore throat size distribution and capillary pressure: The results in the previous sections already demonstrated that the permeability depends on the reduction of pore throat diameter through quartz overgrowth. To verify this pore throat size distribution, mercury injection measurements of six samples used for poro/perm measurements were taken.

The capillary pressure curve was caclulated through oil-brine drainage. The results show pore throat size distribution from 10 to 30 $\mu \mathrm{m}$ (Figure 17) and shows the impact of the permeability reduction on the pore throat sizes. Permeability decreases with decreasing pore throat size and it explains the permeability reduction with a limited decrease in porosity (Figure 15).

The measurements also provide the relation between pressure and water saturation (Figure 18). The results show for samples one pressure step, which means that a narrow range of capillary curves in the porous medium are present. In other words, a narrow band homogeneous throat size distribution.

Centrifuge experiments were performed as a verification of the MICP data (Figure 18). They indicate that the centrifuge results agree with those of the MICP. This is another indication that the Fontainebleau is a homogeneous system with limited band widths in porosity, pore throat diameter and associated permeability.

Both measurements show that the Fontainebleau is strongly water wet. A characteristic feature of the drainage capillary pressure curve for two nearly incompressible fluids (like oil and water) is the minimum value of the wetting-phase saturation; the residual water saturation , is reached asymptotically as the capillary pressure increases toward extreme values (Figure 19).

Di-electric properties: Figure 20 shows a comparison between the conductivity measurements and literature. The set-up has a range of $1000 \mu \mathrm{S} / \mathrm{cm}$ with a precision of $0.01 \mu \mathrm{S} / \mathrm{cm}$.
The conductivity of the saturated brine samples increases in proportion with the salinity (Figure 21). Note that the brine only involved $\mathrm{Na}$ and $\mathrm{Cl}$-ions. In addition, the brine sample conductivity shows a positive correlation with porosity. This is due to the increase of pore throat area size and the creation of more flow area for the electrical current.

The formation factor was calculated from the measured conductivities of the brine and saturated brine in the plugs. Figure 22 shows that, for the low salinity results (30 ppm), the formation factor is not in agreement with the higher brine salinities. This is attributed to the influence of the grain surface conduction and an uncertainty effect caused by the resolution of our set-up which was too low [23]. Therefore, the $30 \mathrm{ppm}$ results have been excluded from analysis.

Comparison with the Literature

Figure 23 compares the literature data from Doyen [4], Gomez [22], Revil [23] and this research. The cementation factor $(1.95-2.05)$ from

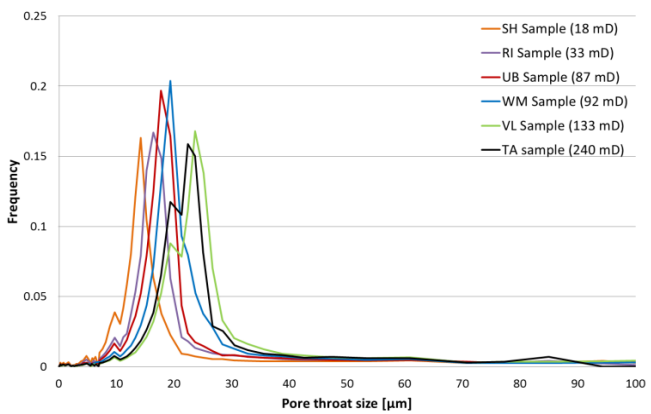

Figure 17: Fontainebleau Pore throat size distribution from MICP.

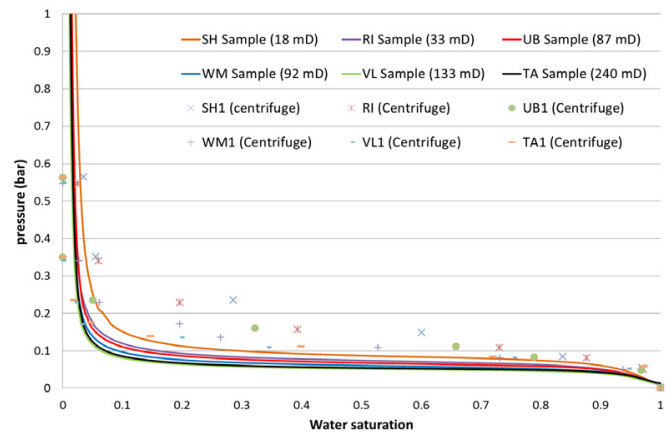

Figure 18: Fontainebleau centrifuge experiments (crosses, dots and lines) compared to the MICP data.

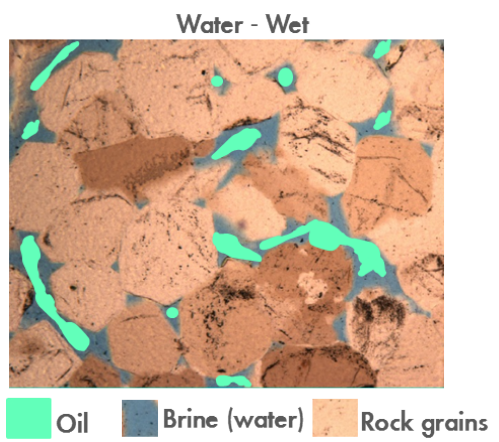

Figure 19: Thin section of Fontainebleau Sandstone. 
Citation: Al Saadi F, Wolf K, Kruijsdijk CV (2017) Characterization of Fontainebleau Sandstone: Quartz Overgrowth and its Impact on Pore-Throat Framework. J Pet Environ Biotechnol 7: 328. doi: 10.4172/2157-7463.1000328

Page 8 of 12

our samples is slightly higher than the literature $(1.8-1.9)$. This could be attributed to two reasons:

Our samples are from the top white clean sandstone and from the same spot. The quartz overgrowth and cementation are more evident and dominating. This is also in line with the cation exchange capacity which shows zero value. The findings in the literature refer to samples from different locations and different horizons in the top layer.

- Our conductivity results cover a small range of porosities $(0.07-$ 0.1 ), which influence the slope (i.e. cementation exponent calculations).

Note that Fontainebleau sandstone exhibits clean sandstone behavior and the measured formation factor follows Archie 1, i.e. a very insignificant clay content. This is in line with the other measurements from XRD/XRF

\section{Zeta Potential Results}

ZetaSizer: For one sample, charged with different brine concentrations, it is clear that the measured zeta potential for Fontainebleau becomes more negative as the salinity decreases (Figure 24).

Empirical relationship between the pore fluid concentration and zeta potential: Pride and Morgan created a relationship to estimate the zeta potential from pore fluid concentration [34]: $\zeta=a+b \log$ $(\mathrm{NaCl})$, where $\zeta$ is the zeta potential $(\mathrm{mV})$ and $(\mathrm{NaCl})$ is the brine fluid concentration $(\mathrm{mol} / \mathrm{l})$.

Revil and Jaafar [35,36] studied this relation over a wide range of fluid concentration in different porous rock types. They concluded that the parameters $\mathrm{a}$ and $\mathrm{b}$ are -6.43 and 20.85 respectively. This empirical equation is shown in Figure 25.

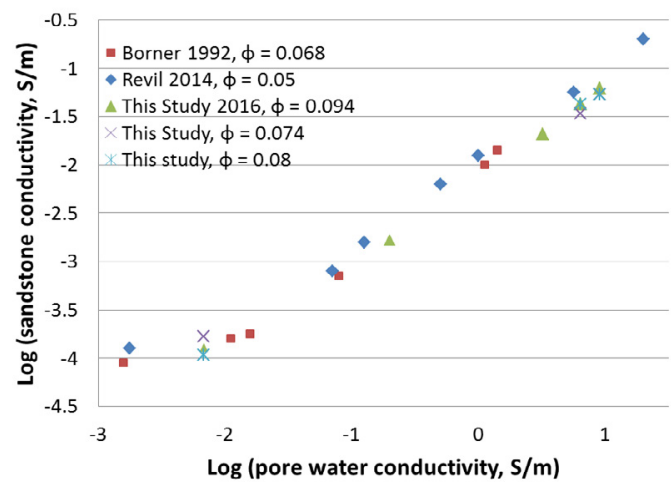

Figure 20: Saturated Fontainebleau sample conductivity vs brine conductivity.

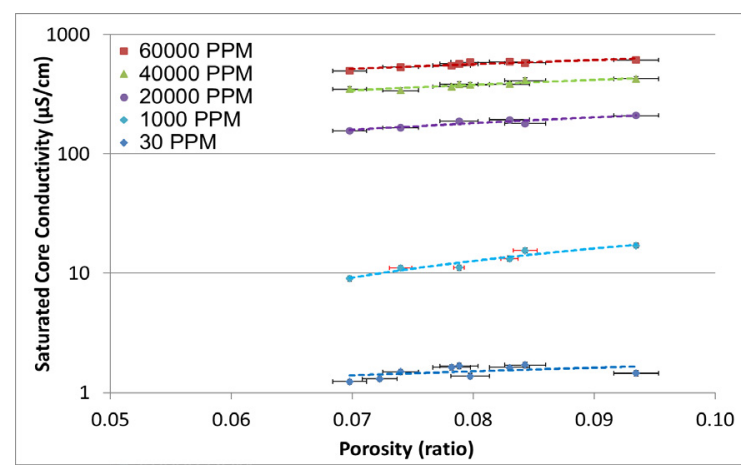

Figure 21: Saturated sandstone brine conductivity versus porosity: both, the $\mathrm{x}$ - and $\mathrm{y}$-error bars are present; however, for $\mathrm{y}$-error is in log scale.

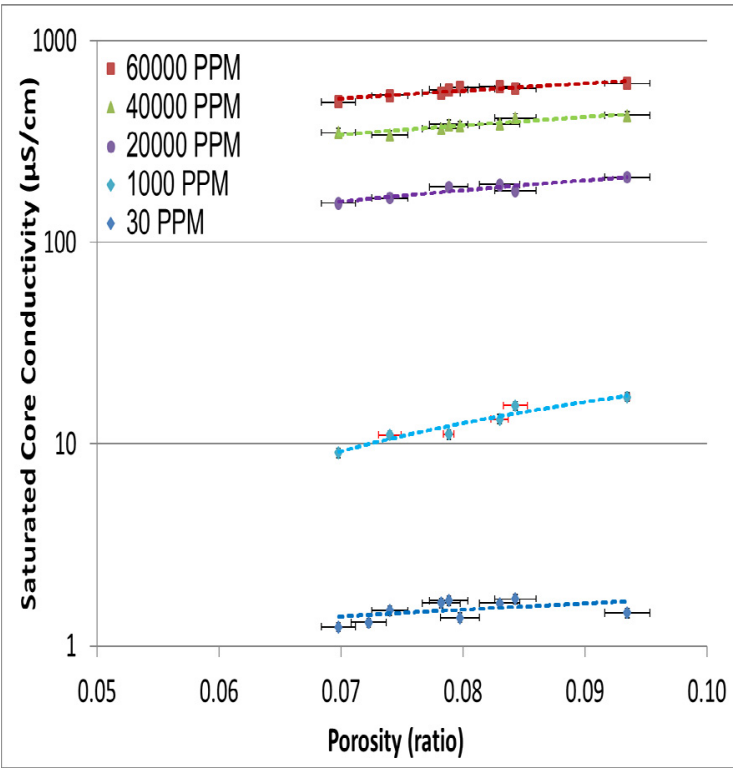

Figure 22: Formation Factor vs Porosity.

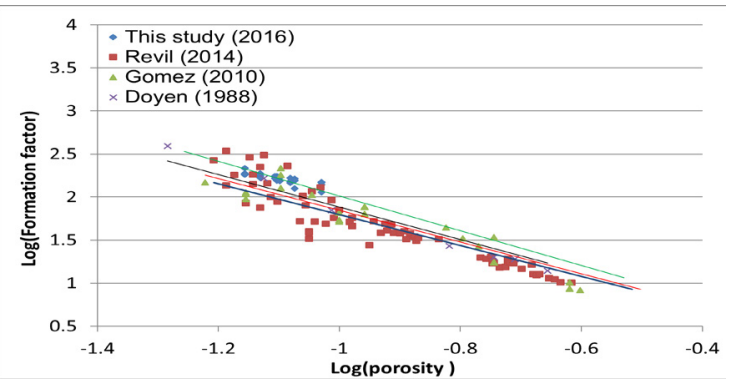

Figure 23: Log (formation factor) vs log (porosity).

Streaming-potential coefficent to zeta potential: literature and experimental data of Fontainebleau sandstone: The streaming potential is the electric potential that is generated when electrolyte fluid flows through a stationary charged solid, such as porous media, by an applied pressure gradient

Helmholtz and Smoluchowsk's theory quantified streaming potential in capillary tubes and they developed an equation knows as HS equation given as:

$$
C_{s}=\frac{\Delta v}{\Delta \mathrm{p}}=\frac{\varepsilon_{r} \varepsilon_{0} \zeta}{\eta_{f} \sigma_{f}}
$$

Here, $C s(\mathrm{~V} / \mathrm{m})$ stands for streaming potential coupling co-efficient and is the ratio of $\Delta \mathrm{V}(\mathrm{V})$ the measured streaming potential to $\Delta \mathrm{P}$ $(\mathrm{Pa})$ the applied fluid pressure difference that drives the fluid through the capillary tube; $\varepsilon_{r}$ is the relative permittivity of the pore fluid; $\varepsilon_{0}$ is the electric permittivity of free space $(\approx 8.85410-12 \mathrm{~F} / \mathrm{m}) ; \eta_{f}$ is the dynamic viscosity of the pore fluid (Pa.s); $\zeta$ refers to zeta potential and $\sigma_{f}$ represents the pore fluid electrical conductivity.

Further modifications in streaming potential formula, mentioned above, have been published by Glover [37] in 2010. They develop formula that links the streaming potential coefficient (Cs) to the zeta potential $(\zeta)$ with respect to the mean pore radius and the mean grain diameter respectively, which yield: 


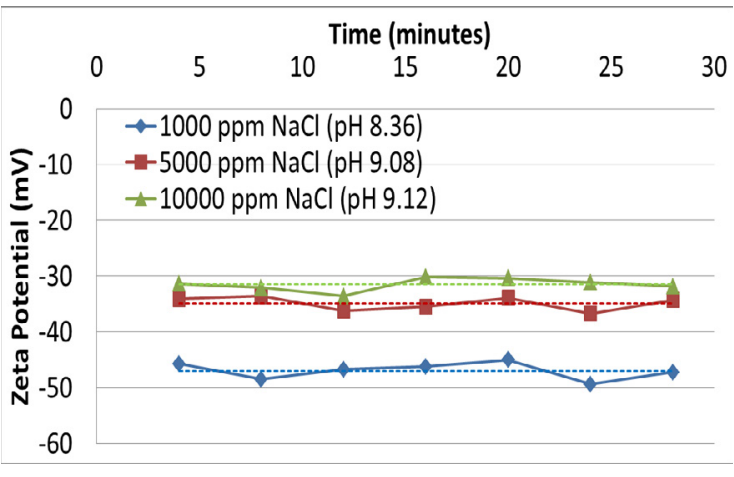

Figure 24: Fontainebleau Zeta Potential and $\mathrm{pH}$ at different brine salinities.

$$
C_{s}=\frac{\Delta v}{\Delta \mathrm{p}}=\frac{\varepsilon_{r} \varepsilon_{0} \zeta}{\eta_{f}\left(d \sigma_{f}+6 \sum_{s}(F-1)\right)}
$$

where, $\Sigma_{s}$ refers to the specific surface conductance, $\mathrm{d}$ is the mean grain diameter and $\mathrm{F}$ is the formation factor,

The streaming potential coupling coefficient in the $\mathrm{NaCl}$ saturated core of Fontainebleau sandstone was measured and the zeta potential was calculated using Eq. 3 and impirical Eq. 4 (Figure 25).

The calculated zeta potential from the streaming potential experimental data is slightly higher. The Zetasizer measurement is a quick and easy method to determine the small amounts of dispersed particles. However, it requires fine-grained crushed rock $(300 \mu \mathrm{m})$. Crushing creates new surface areas and a higher specific area per unit volume, which is considered to be representative for the original larger grains with exponentially less specific pore area. Therefore, the definition of a representative surface sample is important. Figure 25 shows that the measured zeta potential from the Zetasizer is in line with literature data and the empirical equation.

As an alternative, the streaming potential can be measured in exactly the same conditions as the coreflow experiments. However, the methodology of conversion of streaming potentials into zeta potentials needs further investigation because the zeta potential relates directly to a surface of a few grains while the streaming potential is an up-scaled measurement of a core with many more grains and with heterogeneities in pore size and surface composition. The measurements could give an average of the zeta potential of the rock.

Zeta Potential and clay: For a salinity of $5000 \mathrm{ppm}$ of $\mathrm{NaCl}$, the zeta potential decreases with clay content from pure quartz $(-65 \mathrm{mV})$ to $(-15 \mathrm{mV})$ in illite (Figure 26$)$. The surface charge of clay minerals differs from quartz because of its layered crystalline sheet structure with inter and intra-mineral porosity. For sandstones with an increased clay content, the Zetasizer results are within the measurement error and therefore we are not able to observe clay effects in our Fontainebleau

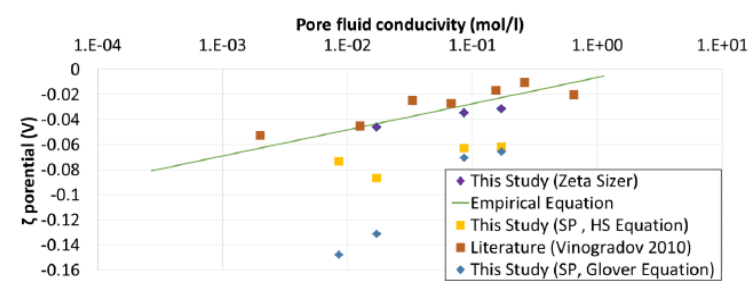

Figure 25: Fontainebleau Zeta potentials.

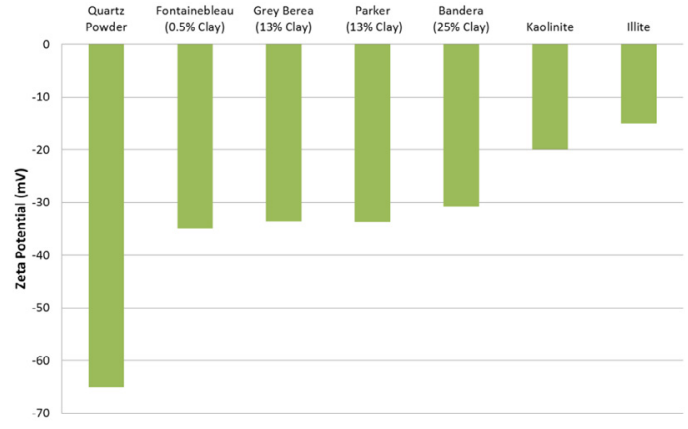

Figure 26: Zeta potential from Zetasizer for different type of minerals and rocks.

sample. The zeta potentials are very $\mathrm{pH}$ sensitive, with less negative zeta potentials at lower $\mathrm{pH}$ values and more negative zeta potentials at higher $\mathrm{pH}$ values. Vinagradov [38] recorded similar results, within experimental error (i.e. 4\%), in samples which do not contain clay [39-44]

\section{Summary of Results}

In this article we summarize the petrophysical characteristics of Fontainebleau sandstone based on the literature to date and our experimental work. Our experimental results are from one sample block of about $0.018 \mathrm{~m}^{3}$, from one specific site and one specific layer; they are compared with results from the entire outcrop area in the vicinity of Paris (France).

The following laboratory experimental methods and image analysis techniques were conducted to characterize the porous media. The techniques used and results are summarized as follow:

\section{Mineralogy}

XRD/XRF data shows that our samples consist of only quartz mineral (0.995). There are traces of other oxides. Synthetically reconstructed clays are illite (0.0015) and kaolinite (0.0039). Polarized light of the thin section images shows that visually only quartz is present; no clays were found in the pores.

\section{Quartz overgrowth}

The quartz overgrowth dictates the cementation around the original grains. It is estimated to be in the range of 0.15 to 0.2 of the bulk volume.

\section{Porosity and Permeability}

The porosity and permeability of Fontainebleau sandstone have a constant bandwidth and do not vary laterally in our sample blocks. Our data set covers a range of porosity of 0.05 to 0.15 which was not properly covered in the literature. By combining literature data, an improved phi/k-relation is developed; $\mathrm{K}=10^{6,5+4,6^{+} \log (\varphi)} ; \mathrm{R}^{2}=0.95$.

\section{Pore and grain framework}

The pore, grain and pore-throat size distribution of our Fontainebleau sandstone appears to be constant and well sorted. Our samples indicate constant pore size $(20-100 \mu \mathrm{m})$, pore-throat size diameter $(10-30 \mu \mathrm{m})$ and grain diameter distributions $(100-300$ $\mu \mathrm{m})$. Concerning capillarity, quartz is the only mineral, making the Fontainebleau system strongly water-wet.

\section{Dielectric properties}

The dielectric measurements exhibit clean sandstone behavior and the measured formation factor follows Archie 1, i.e. very insignificant 
Citation: Al Saadi F, Wolf K, Kruijsdijk CV (2017) Characterization of Fontainebleau Sandstone: Quartz Overgrowth and its Impact on Pore-Throat Framework. J Pet Environ Biotechnol 7: 328. doi: 10.4172/2157-7463.1000328

Page 10 of 12

\begin{tabular}{|c|c|c|c|c|c|c|c|c|}
\hline Reference & Porosity & Permeability mD & Coordination Number & $\begin{array}{l}\text { Throat Size } \\
\mu \mathrm{m}\end{array}$ & $\begin{array}{l}\text { Pore size } \\
\mu \mathrm{m}\end{array}$ & $\begin{array}{l}\text { Channel } \\
\text { Length } \mu \mathrm{m}\end{array}$ & $\begin{array}{l}\text { Grain Density } \\
\text { cc/g }\end{array}$ & Specific Area \\
\hline \multirow{7}{*}{ Doyen 1988} & 5.2 & 4 & 2.3 & 5.8 & 16.1 & & & \\
\hline & 7.5 & 33 & 3 & 5.8 & 13.2 & & & \\
\hline & 9.7 & 54 & 4.4 & 10.4 & 18.9 & & & \\
\hline & 15.2 & 569 & 5.6 & 13.7 & 27.3 & & & \\
\hline & 18 & 593 & 5.9 & 11.7 & 21.8 & & & \\
\hline & 19.5 & 1123 & 5.7 & 16 & 26.8 & & & \\
\hline & 22.1 & 784 & 6 & 18.7 & 30.2 & & & \\
\hline \multirow{4}{*}{ Fredrich 1993} & F1 4.1 & 0.42 & & & 13 & & 2.648 & $0.9 \times 10-4 \mathrm{~m}-1$ \\
\hline & F4 10.3 & 199 & & & 13 & & 2.646 & $\begin{array}{l}2.03 \times 10-4 \\
m-1\end{array}$ \\
\hline & F7 15.5 & 586 & & & 17.6 & & 2.648 & $\begin{array}{l}2.24 \times 10-4 \\
m-1\end{array}$ \\
\hline & F8 20.3 & 4139 & & & 19 & & 2.642 & $\begin{array}{l}1.97 \times 10-4 \\
m-1\end{array}$ \\
\hline Cocker 1996 & 14.8 & 1317 & & & 10 & & & $\begin{array}{l}1.54 \times 10-4 \\
m-1\end{array}$ \\
\hline \multirow{4}{*}{ Lindquist 2000} & 7.5 & & 3.37 & 18.4 & & 198 & & \\
\hline & 13 & & 3.49 & 21.3 & & 159 & & \\
\hline & 15 & & 3.66 & 24.7 & & 154 & & \\
\hline & 22 & & 3.75 & 22.6 & & 131 & & \\
\hline \multirow{2}{*}{ This Study 2016} & 6 & 18 & 3 & $05-20$ & $20-80$ & & 2.64 & $0.0968 \mathrm{~m} 2 / \mathrm{g}$ \\
\hline & 10 & 240 & 3.5 & $10-30$ & $20-80$ & & 2.64 & $0.1066 \mathrm{~m} 2 / \mathrm{g}$ \\
\hline
\end{tabular}

Table 5: Spatial characteristics and permeability from literature [5-8].

clay content. This is in line with the other measurements from XRD/ XRF. Zeta potential measurements show that the Fontainebleau surface charge is negative. This is due to the fact it is composed purely of quartz.

\section{Conclusion}

In conclusion, the porous media of Fontainebleau sandstone reveals homogeneity in its texture and mineralogy due to its pure composition. Clay minerals are almost non-existent and only accessories of clay have been spotted in the inclusion area. It has no impact on the fluid flow behavior during core-flow experiments. This will ensure maximal reproducibility and comparison of fluid flow experimental results.

Furthermore, we demonstrated that the quartz overgrowth (i.e. cementation) is playing a central role in the pore-throat geometry and impacts both permeability and porosity by reducing the pore-throats (i.e. coordination number). By applying the Panda and Lake approach we demonstrated that the permeability of Fontainebleau is impacted more by the quartz overgrowth (i.e. cementation) than the grain size distribution. Moreover, we defined a pore-throat diameter distribution based on the degree of authigenic cementation and porosity. In other words, this microstructure property (i.e. quartz overgrowth) has significant impact on fluid flow. The tortuosity is higher and it influences the path of the fluid during the transport. Note that mapping the pore framework allows us to model the mobilization and transport of the oil on the entire micrometer to meter scale.

Regarding dielectric behavior, the high negative surface charges of the Fontainebleau grains influence the geochemical process (for example adsorption of injected chemicals) when it is used in enhancing the oil mobilization and transport. This will help in pre-defining the experimental protocol for the core-flow experiment.

As a final conclusion, we state that all spatial characteristics do have a direct correlation with porosity, permeability and capillarity. In other words, these cross-textural and physical relations may be used as input parameters for the porosity, permeability and pore throat area distribution outside our experimental scope of research and for modeling purposes.

\section{Acknowledgement}

The authors want to thank the TU Delft technical team (Michiel Slob, Kare Heller, Joost van Meel, Jens van den Berg) for their contributions to the sample preparation, experimental work and image analysis discussions. Special thanks to Fons Marcelis from Shell for SEM, thin sections and BET measurements. Furthermore, we would like to thank staff of the Grès de Fontainebleau \& Cie quarry in Moigny-sur-École for their assistance in the quarry.

\section{List of Abbreviations}

CT: Computed Tomography;

2D: Two Dimensions;

3D: Three Dimensions:

SEM: Scanning Electron Microscopy;

MICP: Mercury Injection Capillary Pressure;

XRD: X-Ray Diffraction

XRF: X-Ray Fluorescence;

EDL: Electrical Double Layer

M3: Mixed Mode Measurement;

PALS: Phase Analysis Light Scattering;

CK: Carmen-Kozeny;

HS: Helmholtz and Smoluchowsk

\section{List of Symbols}

K: Permeability (L);

$\varphi$ : Porosity;

F: Formation Factor;

$C_{w}$ : Conductivity of fully brine saturated rock $(\mu \mathrm{S} / \mathrm{cm})$;

$C_{o}$ : Conductivity of brine $(\mu \mathrm{S} / \mathrm{cm})$;

$m$ : Cementation exponent;

$\alpha$ : Texture factor;

$\bar{D}_{p}$ : Mean particle diameter $(\mathrm{L})$; 
Citation: Al Saadi F, Wolf K, Kruijsdijk CV (2017) Characterization of Fontainebleau Sandstone: Quartz Overgrowth and its Impact on Pore-Throat Framework. J Pet Environ Biotechnol 7: 328. doi: 10.4172/2157-7463.1000328

$D_{P:}$ Diameter of particle (L);

$C_{D P}:$ Coefficient of variation $=$ standard deviation $/$ mean;

Y: Skewness of a particle size distribution;

$\theta$ : Bulk connected porosity, usually measured by helium porosimetry;

$\theta_{0}$ : Porosity of an unconsolidated sand;

$T_{e:}$ Effective tortuosity;

$a_{\mathrm{vb}}$ : Specific surface area of pore-bridging cement $\left(\mathrm{L}^{-1}\right)$;

$a_{v l}$ : Specific surface area of pore-lining cement $\left(L^{-1}\right)$;

$a_{v f}:$ Specific surface area of pore-filling cement $\left(L^{-1}\right)$;

$P_{b}, P_{f}, P_{f}$ : Amount of pore-bridging, pore-lining, and pore-filling cements, fraction of the total solid volume;

$C_{s}$ : Streaming potential coupling co-efficient;

$\zeta$ : Zeta potential.

\section{References}

1. Alimen H (1936) Étude sur le Stampien du Bassin de Paris. Mémoire, *v.31. Société Géologique de France, pp. 1-304.

2. Thiry M, Bertrand-Ayrault M, Grisoni JC (1988) Ground water silicification and leaching in sands: Example of the Fontainebleau Sand (Oligiocene) in the Paris Basin: Geological Society of America. Bulletin 100: 1283-1290.

3. Jacquin C (1964) Correlations between the permeability and the geometric characteristics of the Fontainebleau gres. Rev. Inst. Fr. Pet. 19: 921- 937.

4. Doyen P (1988) Permeability, Conductivity, and Pore Geometry of Sandstone, Journal of Geophysical Research 93: 7729-7740.

5. Fredrich JT, Greaves KH, Martin JW (1993) Pore geometry and transport properties of Fontainebleau sandstone, Int. J. Mech. Min. Sci. Geomech. Abstr 30: 691-697.

6. Coker D, Torquato S, Dunsmuir J (1996) Morphology and physical properties of Fontainebleau sandstone via a tomographic analysis. Journal of Geophysical Research 101: 17,497-17,506.

7. Lindquist WB, Venkatarangan A, Dunsmuir J, Wong T (2000) Pore and throat size distributions measured from synchrotron X-ray tomographic images of Fontainebleau sandstones, Journal of Geophysical Research 105: 21509-21527.

8. Thiry M (1999) Diversity of continental silicification features: examples from the Cenozoic deposits in the Paris Basin and neighbouring basement Palaeoweathering, Palaeosurfaces and Related Continental Deposits, special publication Number 27: 87-127.

9. Dollfus GF (1911) Feuilles de Fontainebleau et de Châteaudun au 80000 . Bull. Serv. Carte Géol. Fr, XXI, 128: 8-30.

10. Thiry M, Marechal B (2001) Development of tightly cemented sandstone lenses in uncemented sands: Example of the Fontainebleau Sand (Oligocene) in the Paris Basin. Journal of Sedimentary Research 71: 473-483.

11. Haddad S, Worden RDJP, Smalley P (2006) Quartz Cement in the Fontainebleau sandstone, Paris Basin, France; Crystallography and implications for mechanisms of cement growth. Journal of Sedimentary Research 244-256.

12. French $M$, Worden $R$ (2013) Orientation of microcrystalline quartz in the Fontainebleau Formation, Paris Basin and why it preserves porosity. Journal of Sedimentary Geology 284-285: 149-158.

13. Zinszner BT (1985) Hydraulic and Acoustic properties as a function of porosity in Fontainebleau Sandstone. Journal of Geophysical Research: Solid Earth 90: 11524-11532.

14. Bourbie T, Zinszner B (1985) Hydraulic and acoustic properties as a function of porosity in Fontainebleau sandstone. Journal of Geophysical Research: Solid Earth 90: 11524-11532.

15. Schon J (2015) Physical properties of rocks, second edition, developments in petroleum science. Elsevier.

16. Tiab D, Donaldson E (2015) Petrophysics: Theory and Practice of Measuring Reservoir Rock and Fluid Transport Properties, fourth edition, Elsevier.

17. David C, Darot M (1989) Permeability and conductivity of sandstones Rock at GreatDepth, Maury \& Fourmaintraux (eds), Rotterdam.
18. Pirson SJ (1963) Handbook of well log analysis. Prentice-Hall Inc, New York.

19. Archie GE (1942) Electrical Resistivity Log as an Aid in Determining Some Reservoir Characteristics, Trans, AIME 146: 54-61.

20. Worthington PF (1993) The uses and abuses of the Archie equations. 1. The formation factor-porosity relationship. J Appl Geophys 30: 215-228.

21. Timur A, Hempkins WB, Worthington AE (1972) Porosity and Pressure Dependence of Formation Resistivity Factor for Sandstones, Formation Evaluation Symposium, Canadian Well Logging Soc, Calgary.

22. Gomez CT, Dvorkin J, Vanorio T (2010) Laboratory measurements of porosity, permeability, resistivity, and velocity on Fontainebleau sandstones. Geophysics 75: E191-E204.

23. Revil A, Kessouri P, Torres-Verdín C (2014) Electrical conductivity, induced polarization, and permeability of the Fontainebleau sandstone. Geophysics 79: D301-D318.

24. Börner F (1992) Complex conductivity measurements of reservoir properties", Proc Third Europ. Core Analysis Symp. Paris 359-386.

25. Wolf $\mathrm{KH}(2006)$ the interaction between underground coal fires and their roof rocks, Phd dissertation/Thesis, TU Delft.

26. Shehata A, Nasr-El-Din H (2015) Zeta Potential Measurements: Impact of Salinity on Sandstone Minerals, SPE International Symposium on Oilfield Chemistry, Texas, USA. SPE-173763.

27. Weiner BB, Tscharnuter WW, Fairhurst D (1993) Zeta Potential: A New Approach, the Canadian Mineral Analysts Meeting, Manitoba, Canada.

28. Leroy P, Devau N, Revil A, Bizi M (2013) Influence of surface conductivity on the apparent zeta potential of amorphous silica nanoparticles. Journal of Colloid and Interface Science 410: 81-93.

29. Lake LW, Johns RT, Rossen B, Pope G (2014) Fundamentals of Enhanced Oil Recovery, Society of Petroleum Engineers.

30. Dullien F (2012) Porous Media: Fluid Transport and Pore Structure, 2nd ed, Howard Brenner.

31. Pickell J, Swanson BF, Hickman WB (1966) Applications of Air-Mercury and OilAir Capillary Pressure Data in the Study of Pore Structure and Fluid Distribution, SPEJ 55-61; Trans. AIME, 237, SPE1227.

32. Panda MN, Larry WL (1994) Estimation of Single-Phase Permeability from Parameters of Particle-Size Distribution, AAPG Bulletin 78: 1028-1039.

33. Panda MN, Larry WL (1995) A Physical Model of Cementation and Its Effects on Single-Phase Permeability, AAPG Bulletin 79: 431-443.

34. Pride S, Morgan FD (1991) Electrokinetic dissipation induced by seismic waves. Geophysics 56: 914-925.

35. Revil A, Pezard PA, Glover PWJ (1999) Streaming potential in porous media: theory of the zeta potential. Journal of Geophysical Research: Solid Earth 104: 20021-20031.

36. Jaafar MZ, Vinogradov J, Jackson MD (2009) Measurement of streaming potential coupling coefficient in sandstones saturated with high salinity $\mathrm{NaCl}$ brine. Geophysical Research Letters.

37. Glover PWJ, Walker E, Jackson MD (2012) Streaming-potential coefficient of reservoir rock: A theoretical model. Geophysics 77: D17-D43.

38. Vinogradov JMZ, Jaafar, Jackson MD (2010) Measurement of streaming potential coupling coefficient in sandstones saturated with natural and artificial brines at high salinity. Journal of Geophysical Research: Solid Earth 115.B12.

39. Zinszner BT (2007) A Geoscientist's Guide to Petrophysics. IPF Publications: Publisher: Editions Technips.

40. Wilson OB, Tjetland BT, Skauge A (2001) Drainage rates in capillary pressure experiments. In: 15th International Symposium of the Society of Core Analysts, No. SCA2001-30, pp. 1-12.

41. Mohanty KK, Davis HT, Scriven LE (1987) Physics of Oil Entrapment in WaterWet Rock". SPE Reservoir Engineering, SPE-9406.

42. Song I (2008) Hydromechanical properties of Fontainebleau sandstone: Experimental determination and micromechanical modeling. Journal of Geophysical research: solid earth, 113 (B9) 
Citation: Al Saadi F, Wolf K, Kruijsdijk CV (2017) Characterization of Fontainebleau Sandstone: Quartz Overgrowth and its Impact on Pore-Throat Framework. J Pet Environ Biotechnol 7: 328. doi: 10.4172/2157-7463.1000328

Page 12 of 12

43. Stegemeier GL (1977) Mechanisms of Entrapment and Mobilization of Oil in Porous Media", in Improved Oil Recovery by Surfactant and Polymer Flooding, Shah DO and Schechter RS. ed, Academic Press, New York.
44. Szymczyk A, Pierre A, Reggiani JC, Pagetti J (1997) Characterisation of the electrokinetic properties of plane inorganic membranes using streaming potential measurements. Journal of membrane science 134: 59-66. 